\title{
Factors associated with maternal choice to provide breast milk for low birthweight infants
}

\author{
A LUCAS, ${ }^{*}$ T J COLE,${ }^{*}$ R MORLEY,${ }^{*}$ P J LUCAS,${ }^{*} \mathrm{~J}$ A DAVIS, $\uparrow$ M F BAMFORD, $\ddagger$ P CROWLE, $\uparrow$ \\ J F B DOSSETOR,§ R PEARSE, ${ }^{* *}$ AND A BOON** \\ ${ }^{*}$ MRC Dunn Nutrition Unit, Cambridge, Departments of Paediatrics, †University of Cambridge, $¥$ Heath \\ Road Hospital, Ipswich, \Norfolk and Norwich Hospital, Norwich, §Queen Elizabeth Hospital, Kings Lynn, \\ and **Jessop Hospital, Sheffield.
}

SUMMARY Factors associated with maternal choice to provide milk for premature infants were investigated in 925 mother/infant pairs in five hospitals. A well educated, married, primiparous mother aged 20 or over who delivered a baby boy by caesarean section was nearly 1000 times more likely to choose to express her milk than a mother who was poorly educated, single, multiparous, and aged under 20 , delivering a female infant vaginally. Evidence from the five centres suggested that hospital staff have little influence on a mother's choice of feeding method. The major differences between the populations of babies whose mothers do or do not choose to provide milk, raise important issues concerning the interpretation of data from non-randomised clinical trials of feeding premature infants.

The use of human milk for feeding premature infants is controversial, but there is a widely held view that mothers should be encouraged to provide their infants with expressed breast milk as the sole diet or in conjunction with supplementary nutrition. Our multicentre feeding studies have shown that over two thirds of mothers choose to provide their premature babies with breast milk. ${ }^{1}$ Data from 925 mother/infant pairs enabled us to find out which factors influence this choice. The subject has already been investigated in mothers of infants born at full term..$^{2-6}$ A similar detailed analysis of data from mothers of premature infants ought to answer two important questions: firstly, whether health professionals in neonatal units exert a major influence on a mother's feeding preference and hence the availability of preterm human milk in the unit; and secondly, whether there are population differences between mothers who do and do not choose to feed their babies, because such information has a bearing on the interpretation of data from the many nonrandomised trials that have compared the effects of mothers' milk with another diet.

\section{Subjects and methods}

Premature infants weighing less than $1850 \mathrm{~g}$ at birth (mean birth weight $1370 \mathrm{~g}$, mean gestation 31 weeks) were entered into a feeding study in five centres between January 1982 and March 1985 . Details of the study design have been published elsewhere. ${ }^{7}$ Mothers were free to decide whether to provide breast milk for their infants. A research nurse approached the mother within 48 hours of delivery to enquire if expressed milk was the intended feeding method; by 72 hours all mothers in the study had decided. This analysis is not concerned with how successful mothers were in providing breast milk, simply whether or not they chose to attempt it.

Table 1 shows the associated factors. Social classes were based on the Registrar General's classification, and birth rank was defined as the birth order of living children, the first born child ranking 1 , and so on. Twins or triplets in this pregnancy were assigned the same rank.

Smoking history was noted. Data on all the mothers' smoking history were not available for this analysis and are being collected. Problems during pregnancy analysed included toxaemia, infections, surgery, anaemia, threatened abortion, and antepartum haemorrhage.

Although 925 mother/infant pairs were studied, information on social class and mother's education was being collected in a formal interview at the time of writing; data were not available for all patients for the analysis of these two factors. 
Table 1 Association between categories and mother's intention to provide breast milk

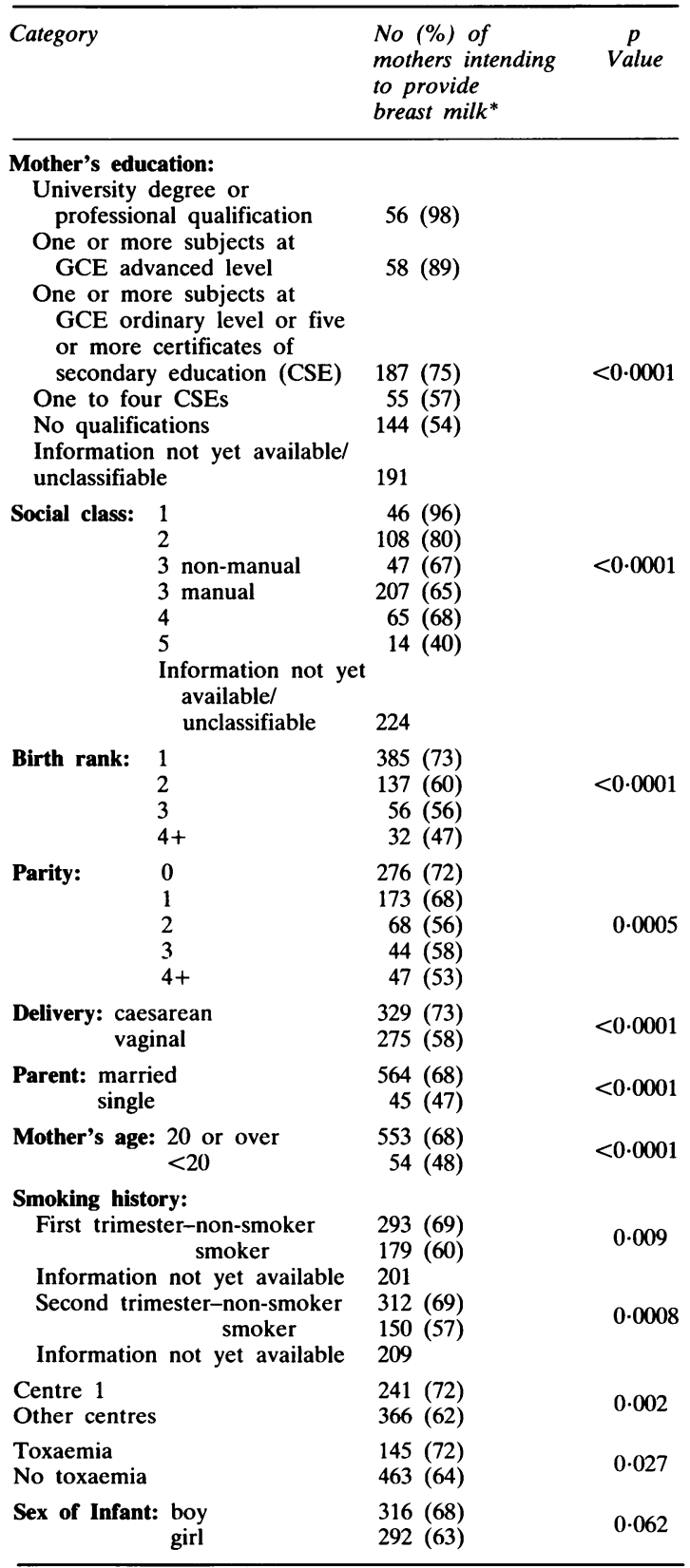

*The percentage is based on the numbers of mothers in each category.
Statistical analysis was by the $\chi^{2}$ test, Student's $t$ test, or logistic regression as appropriate; linear regression was not used because the dependent variable (choice to provide milk), was categorical.

\section{Results}

- In an initial analysis of the 925 mother/infant pairs, several factors were examined individually for their association with the mother's wish to provide breast milk or another type of feed. Table 1 shows that a significantly greater proportion of mothers chose to provide their milk if they were better educated $(p<0.0001)$, came from a higher social class $(\mathrm{p}<0.0001)$, had fewer living children $(\mathrm{p}<0.0001)$ or low parity $(\mathrm{p}=0.0005)$, were delivered by caesarean section $(\mathrm{p}<0.0001)$, or had had toxaemia in pregnancy $(p<0 \cdot 027)$. Conversely, fewer mothers chose to express their milk if they were single parents $(p<0.0001)$, were aged less than $20(p<0 \cdot 0001)$, or if they smoked in the first trimester $(p<0.009)$ orparticularly-in the second trimester $(\mathrm{p}<0.0008)$. There was a strong trend $(p<0 \cdot 06)$ for mothers to provide milk for boys (after adjustment for other factors, this difference reached significance). In one centre (centre 1) a significantly higher proportion of mothers chose to provide breast milk when compared with the other four centres $(\mathrm{p}<0.002)$. Two further factors that were strongly associated with mother's education and social class, and hence with intention to provide breast milk, were maternal height and head circumference (by Student's $t$ test, $\mathrm{p}<0.01)$; maternal weight was not associated.

Factors not associated with the intention to provide milk were: gestational age, birth weight, multiple births, whether the baby was small for gestational age, whether the mother had been transferred from another hospital (except in centre 1), whether the mother lived outside a 10 mile radius of the neonatal unit, whether the father smoked, or whether the pregnancy was complicated by bleeding, infection, operations, or prolonged rupture of membranes.

Table 2 shows the logistic regression model; intention to provide breast milk was the dependent variable. Only those factors in the model that were significantly associated with the dependent variable are shown; these include maternal education, age, birth rank, marital status, the infant's sex, and the mode of delivery. It should be noted that after inclusion of mother's education or social class in the model the following factors associated with intention to provide milk ceased to reach significance: maternal smoking, toxaemia of pregnancy, intercentre differences, and maternal anthropometric measurements. In contrast, the association with 
Table 2 Odds on choosing to provide breast milk for each significantly associated factor in a logistic regression model

\begin{tabular}{|c|c|c|c|}
\hline Factor & $\begin{array}{l}\text { Regression } \\
\text { coefficient }\end{array}$ & t Value & $\begin{array}{l}\text { Odds on } \\
\text { electing to } \\
\text { provide } \\
\text { breast milk }\end{array}$ \\
\hline \multicolumn{4}{|l|}{ Mother's education: } \\
\hline $\begin{array}{l}\text { University degree or } \\
\text { professional qualification } \\
\text { One or more subjects }\end{array}$ & $3 \cdot 59$ & $4 \cdot 3^{* *}$ & $36 \cdot 3: 1$ \\
\hline $\begin{array}{l}\text { at GCE advanced level } \\
\text { One or more subjects } \\
\text { at GCE ordinary level }\end{array}$ & 1.66 & $3 \cdot 9^{* *}$ & $5 \cdot 2: 1$ \\
\hline or four or more CSEs & 0.79 & $4 \cdot 0^{* *}$ & $2 \cdot 2: 1$ \\
\hline Maternal age ( 20 or over) & $0 \cdot 84$ & $2 \cdot 5^{*}$ & $2 \cdot 3: 1$ \\
\hline Birth rank 1 & 0.74 & $3 \cdot 9^{* *}$ & $2 \cdot 1: 1$ \\
\hline Two parent family & $0 \cdot 74$ & $2 \cdot 3^{*}$ & $2 \cdot 1: 1$ \\
\hline Baby boy & 0.45 & $2 \cdot 5^{*}$ & $1 \cdot 6: 1$ \\
\hline Caesarean section & 0.46 & $2 \cdot 5^{*}$ & $1 \cdot 6: 1$ \\
\hline Constant ('worst case') & $-1 \cdot 97$ & & $(0 \cdot 14: 1$ \\
\hline
\end{tabular}

${ }^{* *} \mathrm{p}<0 \cdot 001,{ }^{*} \mathrm{p}<0 \cdot 02$.

having a baby boy increased in significance $(\mathrm{p}<0 \cdot 02)$ after adjustment for other factors. In the 'worst case' for providing breast milk (mother having one to four certificates of secondary education, or no qualifications, age under 20 , birth rank over 1 , single parenthood, female gender and vaginal delivery of baby) the odds on doing so were $0 \cdot 14: 1$ or 1 in 7; the 'best case' odds (mother having a university degree or professional qualifications, and opposites of the above factors) were 128:1.

The constant was set as the 'worst case' for providing breast milk; this was the base line of the model and the odds $(0 \cdot 14: 1)$ are the antilog of the constant. The antilogs of individual regression coefficients represent the relative odds of providing breast milk compared with the corresponding worst category-for example, the odds for a baby boy $v$ a baby girl are $1 \cdot 6: 1$. The influence of individual factors on the absolute odds of a mother providing breast milk is derived as the antilog of the sum of the constant and the individual regression coefficient(s). In the 'best case' the absolute odds are the antilog of the sum plus the regression coefficients for mothers with higher educational qualifications, aged 20 or more, with a child of birth rank 1, married or cohabiting, with a male child born by caesarean section; these odds are 128:1.

In the analysis each mother/infant pair was weighted equally. Thus the choice made by a mother with twins or triplets was represented more than once-in some instances the choice was different for each baby. A further detailed analysis was undertaken in which each mother (rather than each baby) was assessed equally. The associations between two factors-the infant's sex or single parenthood, and the intention to provide milk, were found to be stronger in the 68 mothers who had had multiple births than in those who had singleton births; the significance for these two factors was therefore slightly reduced in the weighted model for all subjects. For other factors, associations were the same as in the non-weighted model.

\section{Discussion}

There is little information on the factors associated with maternal choice to provide breast milk for premature infants. Maternal feeding preference might be influenced by the special circumstances of premature delivery and by the mother's need to provide milk in an unphysiological manner-that is by manual or mechanical expression of the breast.

For some of the factors analysed our data are similar to those obtained for mothers of infants born at term. Maternal education had a strong influence; an analysis of the raw data showed that $98 \%$ of mothers with university degrees or higher professional qualifications chose to provide their milk, compared with $54 \%$ of those with no educational qualifications. A similar trend has been described in babies born at term. ${ }^{489}$ Mothers' feeding preference was better predicted by maternal education than by social class, though social class still showed a strong correlation as in mothers of babies born at term. ${ }^{3} 46$

Some investigators have found that primiparous mothers are more likely to breast feed than multiparous ones ${ }^{1011}$; but others have not. ${ }^{812}$ In this study, after adjusting for other factors, mothers with a first child were over twice as likely to provide their milk than those with one or more living children. Though this might be associated with family commitments, it has been pointed out that multiparous mothers of infants born at term are influenced by their previous experiences of infant feeding ${ }^{13}$ and so the recent increase in the incidence of breast feeding has meant that primiparous mothers could be expected on statistical grounds to have a higher incidence of breast feeding.

The observed association between maternal age and breast feeding in other studies has depended on the method of analysis. Three group analyses have indicated that it is the oldest and youngest mothers who are least likely to breast feed. ${ }^{38}$ In this study we found no less intention to provide milk with advancing age, but in young mothers (under 20 years of age) there was a pronounced reduction in the proportion choosing to do so. Single parents were about half as likely to provide their milk even 
after adjustment for age (single parents have a lower mean age than the rest of the population).

Interestingly, mothers were significantly more likely to provide breast milk for boys. This effect was especially noticeable in mothers with multiple births. Most major studies do not report differences between sexes in the incidence of breast feeding following full term delivery. ${ }^{3} 10$ Duration as opposed to incidence of breast feeding has been observed to be greater in girls for certain subgroups of mother/infant pairs, ${ }^{14}$ but this may be related to the greater 'demand' for nutrients by boys rather than the mother's attitude to the sex of the child. ${ }^{15}$ Sumner and Fritsch ${ }^{16}$ suggested that psychosexual factors might influence the mother's attitude towards breast feeding a baby boy; these investigators monitored telephone requests for medical information by new parents in the period immediately after birth and noted that there were twice as many requests for information about the breast feeding of boys than of girls. In another study, however, ${ }^{17} \mathrm{a}$ similar sex imbalance was found with respect to requested information about bottle feeding, perhaps indicating that there is greater parental concern about boys, though not necessarily implying any sexual connotations. In the present study we did not know what proportion of parents were aware of the poorer clinical outcome of premature baby boys, but such an awareness could have engendered the feeling in the mother that everything possible should be done to help a vulnerable child. The surprisingly high prevalence of mothers choosing to provide breast milk for infants born by complicated delivery (caesarean section) might be explained in similar terms.

Analysis of the raw data (table 1) indicated that cigarette smoking by the mother, especially in the second trimester, gave a negative correlation with the choice to provide breast milk. This effect was no longer significant after adjustment for mother's education but strong trends remained, suggesting that there may be a different attitude to breast feeding among smokers. Guise and Prendergast (unpublished observations) found a significant correlation between smoking and bottle feeding in mothers of babies born at full term; this has also been reported by others. ${ }^{5}$ Paternal smoking behaviour was not found to be significant in this study.

It was interesting that no effect of birth weight or gestational age was found, and even extreme prematurity (47 babies had fused eyelids at birth), seemed to have no influence on the mother's feeding preference. Multiple births, and (with the exception of one centre) transfer to another hospital in the neonatal period, did not seem to deter mothers from choosing to provide breast milk.
It is of clinical relevance to know whether medical staff had any influence on the initial feeding preferences of mothers of premature babies. The five centres in this study (Cambridge, Ipswich, Kings Lynn, Norwich, and Sheffield) differed substantially in nature, degree of specialisation in neonatal intensive care, and distribution of social class of the subjects. It is reasonable to suppose that these centres may also have differed in medical staff attitudes to maternal feeding practice. Three centres took a special interest in human milk feeding and had a human milk bank. The intercentre variation, however, that was observed in maternal feeding preferences (table 1) was not seen after adjustment for differences between centres in social class and mother's education. Hospital staff are therefore unlikely to play a major part in influencing a mother's choice to provide milk for her premature infant, though this might not be the case with respect to the 'success' of mothers who do choose to provide their milk; we are currently investigating this hypothesis.

We have shown that the population of infants whose mothers choose to breast feed them differs from the population of infants whose mothers do not. This has important implications for the interpretation of published data from trials of feeding preterm infants and for design of future trials. A non-random comparison of the clinical outcome in infants fed maternal milk and those fed-for instance-on a formula would be misleading in that some major differences in outcome might be associated with group differences in factors such as social class, method of delivery, birth rank, parents' behaviour, and sex distribution rather than with diet alone.

Our findings have shown that a mother's choice to provide breast milk for her premature infant is largely predictable from her education, parity, method of delivery, age, whether she is a single parent or not, and from the sex of the infant. In those mothers for whom all these factors are against providing milk, there is a 1:7 chance of doing so. In contrast, when these factors are in favour, the chances are 128:1; thus in the 'best' case there is nearly a 1000 times greater chance than in the 'worst'.

We thank Farley Health Products Ltd for financial support.

\footnotetext{
References

${ }^{1}$ Lucas A. Availability of preterm milk. Lancet 1983;i:1045-6. 2 Lyon AJ. Factors influencing breast feeding. Acta Paediatr Scand 1984;73:268-70.

${ }^{3}$ Biering-Sørensen F, Hilden J, Biering-Sørensen K. Breastfeeding in Copenhagen, 1938-1977. Dan Med Bull 1980;27: $42-8$
} 
52 Lucas, Cole, Morley, Lucas, Davis, Bamford, Crowle, Dossetor, Pearse, and Boon

${ }^{4}$ Maccaig H, Smart JL. Infant feeding: mothers' antenatal attitudes and subsequent practices. Proc Nutr Soc 1980;39:18A.

5 Lyon AJ. The effects of smoking on breast feeding. Arch Dis Child 1983;58:378-80.

6 Verronen P, Tamminen T. Factors influencing breast feeding. Acta Paediatr Scand 1984;73:268-70.

7 Lucas A, Gore SM, Cole TJ, et al. A multicentre trial on the feeding of low birthweight infants: effects of diet on early growth. Arch Dis Child 1984;59:722-30.

8 Klackenberg G, Klackenberg-Larsson I. The development of children in a Swedish urban community. V. Breast-feeding and weaning: some social-psychological aspects. Acta Paediatr Scand 1968;187(suppl):94-104.

9 Cunningham AS. Morbidity in breast fed and artificially fed infants. J Pediatr 1977;90:726-9.

10 Treuherz J, Cullinan TR, Saunders DI. Determinants of infantfeeding practice in East London. Hum Nutr Appl Nutr 1982; 36A:281-6.

11 Bacon CJ, Wylie JM. Mother's attitudes to infant feeding at Newcastle General Hospital in summer 1975. Br Med J 1976;i:308-9.

12 Roberts DW. Growth of breast fed and bottle fed infants. $N Z$ Med J 1980;92:45-6.

13 Hally MR, Bond J, Crawly J, Gregson B, Philips P, Russell I. Factors influencing the feeding of first-born infants. Acta Paediatr Scand 1984;73:33-9.

14 Thoman EB, Leiderman PH, Olson JP. Neonate-mother interaction during breast-feeding. Developments in Psychology 1972; 6:110-8.

${ }^{15}$ Pao EM, Himes JM, Roche AF. Milk intakes and feeding patterns of breast-fed infants. J Am Diet Assoc 1980;77:540-5.

16 Sumner G, Fritsch J. Postnatal parental concerns: the first six weeks of life. JOGN Nursing 1977;6:27-32.

17 Adebonojo FO. Artificial vs breast feeding: relation to infant health in a middle class American community. Clin Pediatr 1972;11:25-9.

Correspondence to Dr A Lucas, MRC Dunn Nutrition Unit, Milton Road, Cambridge CB4 1XJ.

Received 11 August 1987 